\title{
Environmental Issues Are Health
}

\section{Issues}

\section{Making a Case and Setting an Agenda for Environmental Health Psychology}

\author{
Jennifer Inauen ${ }^{1}$ (D), Nadja Contzen ${ }^{2,3}$, Vivan Frick ${ }^{4}$, Philipp Kadel ${ }^{5}$, Jan Keller ${ }^{6}$, \\ Josianne Kollmann ${ }^{7}$, Jutta Mata ${ }^{5,8}$, and Anne M. van Valkengoed ${ }^{3}$ \\ ${ }^{1}$ Department of Health Psychology and Behavioral Medicine, Institute of Psychology, University of Bern, Switzerland \\ ${ }^{2}$ Eawag: Swiss Federal Institute of Aquatic Science \& Technology, Duebendorf, Switzerland \\ ${ }^{3}$ Faculty of Behavioural and Social Sciences, University of Groningen, The Netherlands \\ ${ }^{4}$ Institute for Ecological Economy Research (IÖW), Center for Technology and Society, TU Berlin, Germany \\ ${ }^{5}$ School of Social Sciences, Chair of Health Psychology, University of Mannheim, Germany \\ ${ }^{6}$ Department of Education and Psychology, Freie Universität Berlin, Germany \\ ${ }^{7}$ Department of Psychology, University of Konstanz, Germany \\ ${ }^{8}$ Mannheim Center for Data Science, University of Mannheim, Germany
}

\begin{abstract}
Increasing demands on ecosystems, decreasing biodiversity, and climate change are among the most pressing environmental issues of our time. As changing weather conditions are leading to increased vector-borne diseases and heat- and flood-related deaths, it is entering collective consciousness: environmental issues are human health issues. In public health, the field addressing these issues is known as environmental health. This field addresses both the effects people have on their environment as well as the effects of the environment on people. Psychology, as a discipline concerned with explaining, predicting, and changing behavior has much to contribute to these issues because human behavior is key in promoting environmental health. To date, however, an integrative view of environmental health in psychology is lacking, hampering urgently needed progress. In this paper, we review how the environment and human health are intertwined, and that much can be gained through a systemic view of environmental health in psychology. Based on a review of the literature, we suggest that psychologists unite efforts to promote an integrative science and practice of environmental health psychology, and jointly address environmental-health related behavior. The research agenda for this field will include integrating behavior change theory and intervention approaches. Thereby, psychology can potentially make an important contribution to sustained environmental health for generations to come.
\end{abstract}

Keywords: environmental health, science of behavior change, health psychology, environmental psychology, intervention

Temperatures are rising, extreme weather is increasing, and water and other natural resources are declining amidst increasing demand by the human population (IPCC, 2014). These and further environmental issues are threatening human life on the planet (Steffen et al., 2015). The magnitude of these environmental issues is now markedly entering the collective consciousness as the voices reminding us of the impact of today's decisions on future generations grow louder (e.g., Thunberg, 2019). Individuals and households contribute significantly to environmental issues (Clayton et al., 2015). For example, 26\% of the total energy consumed in the European Union in 2018 were directly consumed by households, for example, for heating or cooking, and half of that energy originated from fossil fuels, especially gas (eurostat, 2020). In turn, environmental issues affect human health and well-being (G. W. Evans, 2019), which can in part be reduced by people's adaptation to environmental issues (van Valkengoed \& Steg, 2019). Psychology, a discipline concerned with explaining, predicting, and changing behavior, therefore, has much to offer to the mitigation of environmental issues and the promotion of environmental health (Clayton et al., 2015; Otto et al., 2014; Stern, 2011; sometimes also described as planetary health; Swinburn et al., 2019).

Environmental health, "[i]n its broadest sense, ... is the segment of public health that is concerned with assessing, understanding, and controlling the impacts of people on their environment and the impacts of the environment on them" (Moeller, 2011, p. 3). It includes environmental issues such as air pollution, climate change, water, and 
sanitation. Whereas environmental health is an established segment of public health, psychological research on this topic is scattered, hampering urgently needed progress. In particular, two sub-disciplines of psychology are each partially concerned with environmental health: environmental psychology and health psychology. Contributing to the understanding of people's impact on their environment, in the past decades, environmental psychologists have researched the drivers and barriers of pro-environmental behavior and developed effective interventions to promote behavior change, for example, for energy conservation (Abrahamse et al., 2005; Andor \& Fels, 2018), travel mode choice (Lind et al., 2015), and recycling (Varotto \& Spagnolli, 2017). Environmental psychology is further concerned with the impact of the environment on people, especially on their well-being (e.g., favorable impacts of green spaces; Houlden et al., 2018). However, the impact of environmental issues on people's physical health has received comparatively less attention from psychologists and has only recently emerged as a topic of interest in our field (van Valkengoed \& Steg, 2019). This, even though it has been highlighted that environmental issues are ultimately health issues as both are inherently interconnected (EASAC, 2019; Raworth, 2017; Swinburn et al., 2019).

Health psychology, a sub-discipline of psychology dedicated to preventing disease and promoting health and well-being (Matarazzo, 1980) may offer key insights to understanding and promoting environmental health, thereby complementing environmental psychology. However, health psychology has arguably paid less attention to environmental factors, traditionally focusing on the individual's role in health (Matarazzo, 1980), that is, self-regulation to prevent chronic disease (e.g., Schwarzer et al., 2011). Researchers have previously suggested synergies between environmental and health psychology (e.g., Bernard, 2019). Nisbet and Gick (2008), for example, convincingly argued that health psychology may enhance our understanding of pro-environmental behavior. Yet, although some applications of health behavior change models to explain pro-environmental behavior exist (Bamberg, 2013), crosspollination between health and environmental psychology is still rare.

In this paper, we aim to show that much can be gained from an integrated view of environmental health in psychological science and practice. Environmental and health psychology each contribute unique theoretical and methodological approaches and insights to understanding and promoting environmental health. Health psychology can add to our understanding and promotion of behaviors that can mitigate people's impact on the environment (Bernard, 2019), which have traditionally been the focus of environmental psychology. We will henceforth refer to these as "mitigation behaviors" (Bernard, 2019) to avoid precluding

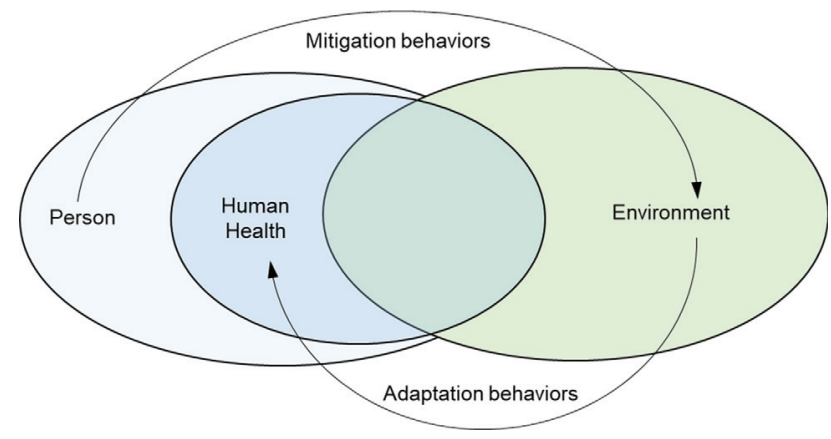

Figure 1. Environmental health psychology: Addressing mitigation and adaptation behaviors related to environmental health.

the motives that drive these behaviors (e.g., proenvironmental or health motives). Further, integration of environmental and health psychology will expand our understanding of behaviors that aim to prevent the adverse impact of environmental issues on human health (henceforth referred to as "adaptation behaviors"; Bernard, 2019). Adaptation behaviors may be conceptualized as health behaviors, but they may also relate back to the environment (e.g., by fostering pro-environmental motives). In summary, our paper makes the case that conceptualizing and addressing environmental health in an integrated manner in psychology (i.e., as environmental health psychology) should significantly enhance understanding and promotion of environmental health. Environmental health psychology will address both mitigation and adaptation behaviors related to environmental health (see Figure 1). The aim is that this integration will enable efficient progress in this field, which is urgently needed considering the pressing nature of environmental issues.

\section{Environmental Health and the Role of Human Behavior}

Major planetary processes such as climate and biodiversity are key to keeping the earth in a Holocene-like state conducive to human life (Raworth, 2017). However, human activities, such as agriculture, industry, and mineral extraction, are altering these processes at a large scale (IPCC, 2018), putting the planet at increased risk of destabilization (Raworth, 2017; Steffen et al., 2015). Already, environmental issues are causing adverse effects on human health. The pollution of drinking water, for example, caused by insufficient sanitation, can lead to the outbreak of waterborne diseases such as typhoid fever and cholera (Schwarzenbach et al., 2010). Chemical pollution of water and soil (e.g., by pesticides) has multiple health effects that are likely 
underestimated (Landrigan et al., 2018). Further, burning fossil fuels leads to widespread air pollution, causing diseases such as asthma and bronchitis (Künzli et al., 2000), and relates to 4.2 million premature deaths annually (WHO, 2019). Importantly, burning fossil fuels is the main source of $\mathrm{CO}_{2}$ emissions, a greenhouse gas that contributes to climate change (Watts et al., 2015).

Climate change is a key environmental issue that poses several direct and indirect health risks (Watts et al., 2015) that will likely be of increasing importance as climate change accelerates. The direct effects of climate change include increases in the frequency and severity of hydrometeorological hazards, such as wildfires, droughts, and flooding (Sauerborn \& Ebi, 2012), which can lead to physical injury and death. Moreover, experiencing such hazards can cause psychological illness such as post-traumatic stress disorder and anxiety (Clayton et al., 2017; Goldmann \& Galea, 2014). Indirectly, climate change adversely affects human health by enabling the spread of vector-borne diseases (e.g., malaria, dengue fever) through fostering favorable conditions for vectors (Campbell-Lendrum et al., 2015). Other examples include food insecurity (climate change increases crop failure, loss of livestock, and agricultural plagues; FAO, 2008), and the possibility of increased armed conflict (Adams et al., 2018; Mach et al., 2019). In addition, psychological consequences are expected, such as psychological distress (G. W. Evans, 2019), and "ecoanxiety" (Clayton et al., 2017).

People's behavior is key to promoting environmental health. On the one hand, people can mitigate their adverse impact on the environment by changing their behaviors. Mitigation behaviors thus aim to alleviate the human impact on the environment. On the other hand, people can avoid or reduce adverse health effects of the environment by adapting to environmental issues. We discuss the two environmental-health related behavioral domains (mitigation and adaptation behaviors) in more detail in the following.

\section{Mitigating Adverse Impact of Humans on the Environment: Mitigation Behaviors}

Through lifestyle changes, individuals and households can mitigate adverse human impact on the environment (IPCC, 2018). For example, people can walk instead of taking the car. They can engage in recycling, or using safe sanitation. They can avoid behaviors such as air travel, consuming meat, using pesticides, and they can adopt sustainable innovations, such as new technologies (e.g., solar power) or new products (e.g., insect-based foods).

Mitigation behaviors have been traditionally addressed in environmental psychology, for example, in the context of pursuing pro-environmental goals (Kaiser \& Wilson, 2004). However, mitigation behaviors can also be relevant from a health perspective when they have co-benefits (Bain et al., 2016). Co-beneficial behaviors reduce people's impact on the environment and simultaneously and directly promote personal health as well. Hence, integrating environmental and health psychology perspectives when addressing mitigation behaviors could valuably extend previous research in this field.

Mitigation behaviors with co-benefits include, for example, meat-reduced diets and active mobility. Compared to other foods, meat production accounts for a substantial amount of greenhouse gas emissions, land use, use of natural resources (e.g., water), and pollution (Clark et al., 2019). Lowering meat consumption or switching to a vegetarian diet could reduce up to $50 \%$ of greenhouse gas emissions and land demand of the current diet (Hallström et al., 2015) while also reducing the risk of coronary heart disease, cancer, type 2 diabetes, and overall mortality (Godfray et al., 2018). Similarly, commuting to work by bicycle or walking instead of taking the car may lower greenhouse gas emissions and fossil fuel consumption, while at the same time increasing air quality, and levels of physical activity (Barnett et al., 2019). This, in turn, will promote better health and well-being (Kelley et al., 2018; Lee et al., 2012; Mata et al., 2012). In addition, mitigation behaviors with co-benefits for well-being and the environment have also been identified. For example, engaging in environmental activism has been shown to relate to greater well-being and health (Klar \& Kasser, 2009).

\section{Reducing Adverse Impacts of the Environment on Human Health: Adaptation Behaviors}

People can take multiple actions to prevent or reduce environmental impacts on human health and well-being (van Valkengoed \& Steg, 2019). These behaviors may or may not be motivated by health concerns, wherefore we advocate an integrated view of psychological science on these behaviors. Adaptation behaviors can be categorized as information seeking, preparative actions, and protective actions (van Valkengoed \& Steg, 2019). Information seeking means acquiring information about a person's risk of an environmental hazard and potential behavioral responses to certain hazards, for example, checking government brochures and monitoring air pollution (e.g., Lewis \& Edwards, 2016). Preparative actions are structural measures that are taken before the onset of an environmental hazard, aimed at reducing the probability of being affected. Examples include flood proofing the home, or buying facemask respirators to protect against air pollution (e.g., 
Hansstein \& Echegaray, 2018). Protective actions are behaviors taken in response to an ongoing hazard, aimed at reducing the impacts of that hazard, for instance, taking prophylactic medicine for vector-borne diseases, or wearing a face mask respirator in an air-polluted area (e.g., Zhou et al., 2016).

Adaptation behaviors affect human health at different timescales. There are behaviors with immediate health effects, such as avoiding overexertion during heatwaves (Akompab et al., 2013). Behaviors could also have intermediate-term effects, such as taking structural measures to ensure indoor temperatures are regulated during a heatwave (Murtagh et al., 2019). There are also behaviors with long-term health effects such as migrating away from affected areas (Zander et al., 2019). Furthermore, most people are facing multiple environmental hazards simultaneously. A broad repertoire of adaptation behaviors will therefore be required in the future, wherefore this is an important emerging field in psychology.

\section{Understanding and Promoting Environmental Health: The Role of Psychology}

As elaborated above, human behavior plays a pivotal role in environmental health, even though psychologists have rarely systemically tackled this. A key contribution of psychology as a discipline, and environmental and health psychology, in particular, is the development of theories about the determinants of behavior change, and the development of behavior change interventions based on these theories. In the following, we provide a brief integrative review of the determinants of mitigation and adaptation behaviors from both environmental and health psychology.

\section{Determinants of Mitigation and Adaptation Behaviors}

Both environmental and health psychology are concerned with explaining mitigation and adaptation behaviors, and their theories show large overlap. Risk perception, a construct from protection motivation theory (Rogers, 1975), for example, plays a role in explaining health behaviors, such as vaccination uptake (Brewer et al., 2007), but can also be used to explain pro-environmental behaviors (Brügger et al., 2015). In addition, people are assumed more likely to engage in behavior change if they expect positive outcomes of the behavior (outcome expectations). While health behaviors are usually motivated by positive personal outcomes, such as promoting personal health, pro- environmental behaviors are usually encouraged by positive collective outcomes, such as improved environmental quality or public health. Accordingly, self-transcendence values (i.e. biospheric and altruistic values) that elicit a moral obligation (personal norm) to act have been identified as key motivators of pro-environmental behaviors (Stern et al., 1999). Further, perceiving oneself as capable of performing a behavior (self-efficacy; Bandura, 1997), as well as social norms, have been theorized as key correlates of behavior change (Ajzen, 1991). Most theories assume that a key step to behavior change is forming a behavioral intention, (Ajzen, 1991; Schwarzer, 2008).

Despite good intentions, many people fail to translate their intentions into action (intention-behavior gap; Orbell \& Sheeran, 1998). Behavior change frameworks such as the health action process approach (HAPA; Schwarzer, 2008; Zhang et al., 2019) focus on volitional behavioral determinants beyond people's intentions. Volitional strategies such as action planning (a detailed plan, where, when, and how to perform a behavior; Leventhal et al., 1965) and action control (Sniehotta et al., 2005; e.g., monitor whether one is wearing facemask respirators in air polluted areas; Zhou et al., 2016) can be further important behavioral determinants. These are often studied in health psychology. Further, automatic processes, such as habits (cue-behavior associations with a history of repetition; Fleetwood, 2019) are gaining renewed attention as predictors of behavior. Finally, contextual factors, referring to environmental and structural aspects that might enable or hinder behavior can be important (Steg \& Vlek, 2009). For example, simply the availability of public transport, recycling facilities, and environmental alternatives in the supermarket are necessary for relevant behaviors to take place (Steg \& Vlek, 2009).

Overall, behavior change theories in environmental and health psychology share many overlaps in the key determinants of behavior change as they play a role in both mitigation and adaptation behaviors. Surprisingly, the exchange between the two sub-disciplines has been limited, despite the strong links between environmental and health issues highlighted previously (Bernard, 2019; Nisbet \& Gick, 2008).

\section{Interventions to Promote Behavior Change}

Based on behavior change theory, interventions can be derived to promote mitigation and adaptation behaviors. An important achievement of psychologists in this field to date has been to make this process systematic. We now have a taxonomy of behavior change techniques (BCTs), that is, the smallest units of interventions that can bring about change, which makes intervention reporting more transparent (Michie et al., 2013). The latest work has also linked BCTs with behavioral determinants, facilitating the 
selection of behavior change techniques for specific behavioral determinants (Carey et al., 2019; Connell et al., 2019). While this work has recently strongly been driven by health psychology, these procedures and tools are readily applicable to the broader environmental health context. Yet, this has rarely been done.

Different theories suggest different ways for promoting behavior change. According to stage models (Bamberg, 2013; Schwarzer, 2008), interventions can be tailored to two general mindsets. For individuals not yet motivated to change (i.e., non-intenders), motivational intervention techniques can aim to create behavioral intentions ("I want to cycle to work, instead of using the car"). For individuals motivated to change, but not performing the behavior (i.e., intenders), volitional intervention techniques could target behavioral adoption and long-term maintenance.

To motivate non-intenders to adopt environmentalhealth behaviors, research has focused on behavioral determinants such as social norms (e.g., Schultz et al., 2016), perceived costs and benefits, or self-efficacy (Steg $\&$ Vlek, 2009). These interventions may address collective goals (e.g., improve quality of nature or public health) or individual goals (e.g., improve the personal financial situation or improve personal health; De Dominicis et al., 2017), and should be matched to recipients' values (van den Broek et al., 2017). For example, pro-environmental framing has been shown to motivate some persons, whereas others are better motivated by monetary framing (Steinhorst et al., 2015), health framing (Carfora et al., 2019), or social justice (Kals, 1996). Herein also lies the potential of promoting behaviors that have co-benefits for health and the environment. The psychological distance of adverse effects of climate change has been found to be a barrier to mitigation behaviors (Jones et al., 2017). Health behavioral consequences, in turn, might be perceived as more proximal. Depending on the mindset of the target population, interventions may thus either emphasize the health benefits of, for example, active mobility or meatreduced diets, or their benefits for the environment (Bain et al., 2016). Emphasizing the more proximal health consequences could be promising to motivate those for whom the environmental consequences seem distal. For others (e.g., younger age groups), the health consequences of their behaviors might seem distal, whereas their concern about climate change can be higher than in older age groups (Corner et al., 2015). Research on this promising pathway to promoting mitigation behaviors should take into consideration spillover effects (i.e., beneficial effects on nontargeted mitigation behaviors) as some self-interest motives (e.g., monetary) have been shown to limit spillover (L. Evans et al., 2013).

People who are motivated, but do not act accordingly exhibit the intention-behavior gap (i.e., monitoring goal progress and investing self-regulatory effort in goal pursuit ; Sniehotta et al., 2005; Bamberg, 2013; Inauen et al., 2016; Orbell \& Sheeran, 1998). These persons benefit from volitional interventions, including planning, action control, or habit formation (Hagger \& Luszczynska, 2014; Verplanken et al., 2018). For instance, individuals can form individual plans on when, where, and how to perform environmental health-related behaviors (Bamberg, 2002), which can be followed up by means of action control (i.e., self-monitoring goal progress and exerting self-regulatory effort in goal pursuit; Sniehotta et al., 2005).

\section{Accelerating Progress: An Agenda for Environmental Health Psychology}

As shown in this paper, there is a substantial need and scope for psychology to contribute to promoting environmental health as behavior change is a key factor. In line with a systemic view of environmental health (Swinburn et al., 2019), and given the considerable overlap and potential synergies between environmental and health psychology, it seems fruitful that both sub-disciplines join forces as environmental health psychology, dedicated to accelerating psychological research and practice related to environmental health. Further psychology sub-disciplines may also contribute, such as clinical psychology (environmental issues also have important effects on mental health; Clayton et al., 2017), or positive psychology (mitigation behaviors can promote well-being; Hunecke, 2013). Below, we outline a research agenda for environmental health psychology, delineating theoretical and applied research questions that should be addressed by psychologists aiming to tackle environmental health.

\section{Toward an Integrative Understanding of Environmental Health in Psychology}

As shown, environmental and health psychology offer synergistic perspectives to enhance our understanding of environmental health. By tackling both the impacts of humans on the environment as well as environmental impacts on human health, environmental health psychology has the potential to lead to a holistic understanding of human behavior related to environmental health. Environmental psychology has already made great progress in understanding mitigation behaviors that help preserve the environment. This line of research may be further enhanced by systematically integrating insights from health psychology, 
for example, by including volitional factors from health behavior theories, such as action control (Sniehotta et al., 2005). Good examples of such theoretical integration exist (Bamberg, 2013; Mosler, 2012). However, this research should be expanded further. We hope that our conceptualization of environmental health psychology, and mitigation and adaptation behaviors specifically, will promote such integrative efforts beyond traditional sub-disciplinary boundaries in psychology. For example, a fruitful avenue for this integrative research may be addressing mitigation behaviors that are beneficial to both the environment and human health.

In terms of adaptation behaviors, an important agenda item for environmental health psychology is to intensify psychological science on behaviors that help humans adapt to environmental risks and reduce their effects on human health. These include, for example, using mosquito nets to prevent vector-borne diseases, using face-mask respirators to prevent respiratory diseases from air pollution, or avoiding the impacts of flooding and wildfires. There is research in psychology that has tackled adaptation to environmental risks, especially regarding climate-related hazards (reviewed in van Valkengoed \& Steg, 2019), but also regarding pollution of drinking water (e.g., Contzen \& Marks, 2018; Inauen et al., 2013), and other pollutants (e.g., Landes et al., 2019; Weinstein et al., 1998). This research should be expanded in light of the pressing environmental issues (e.g., climate change; IPCC, 2014). Further, mental health outcomes are also an important but often overlooked consequence of environmental issues that require psychologists increased attention. Overall, our understanding of human adaptation to environmental issues will benefit from being addressed systemically and jointly by the related psychology sub-disciplines.

\section{Strengthening Intervention Approaches}

An integrative sub-discipline of environmental health psychology should also strengthen behavior change intervention approaches to promote environmental health. Both health and environmental psychology have developed systematic behavior change intervention approaches, such as the behavior change wheel (Michie et al., 2014) or the RANAS approach (risk, attitudes, norms, ability, self-regulation; Mosler, 2012). However, due to low exchange between the sub-disciplines, frameworks have been developed in parallel, hampering cumulative scientific progress. To accelerate research on environmental health promotion, the stronger exchange between environmental and health psychologists concerned with promoting environmental health is therefore highly recommended. This may be achieved, for example, by organizing joint symposia at respective sub-disciplinary conferences.
Combining approaches from environmental and health psychology further provides a chance to promote mitigation behaviors in different ways. For example, motivating people by emphasizing the environmental benefits of their behavior and not only focusing on health benefits could be particularly useful for target groups who are more sensitive to environmental issues than health, such as younger people.

Finally, another important avenue for future research on environmental health promotion is the field of behavior change using digital technology. Social media, for example, are gaining momentum in the context of environmental health (e.g., Frick \& Santarius, 2019; Gosling \& Mason, 2015). Further, smartphone applications allow monitoring of and providing immediate feedback regarding one's behaviors over long periods of time and sharing these with the community (Mata \& Baumann, 2017), thereby promoting social norms. Another promising avenue is just-in-time adaptive interventions (Hardeman et al., 2019; NahumShani et al., 2018) that are used to deliver interventions in critical situations when persons are most susceptible to behavioral changes.

\section{Recommendations for Practice}

Besides research, there are also key recommendations for practice resulting from integrated environmental health psychology. A campaign integrating a holistic environmental health perspective founded in rigorous psychological theory and methods should likely be more effective to promote environmental-health related behavior. First, psychologists apply systematic, theory- and evidence-based approaches that likely tackle key behavioral determinants for the target population, link them with specific behavior change techniques, and evaluate their effectiveness with the required methodological rigor. Thereby, psychologists facilitate progress and learning. Guidelines for systematic behavior change are readily available and include, for example, the behavior change wheel (Michie et al., 2014), intervention mapping (Kok et al., 2004), and the RANAS approach (Mosler, 2012).

Second, a holistic perspective of environmental health should help to tackle people with different motives (e.g., health or pro-environmental motives). As stated above, one essential barrier for engaging in environmental healthrelated behaviors is the high psychological distance of the negative effects of environmental issues such as climate change (Jones et al., 2017). In an effort to reduce psychological distance, and making environmental issues feel urgent and personal (Stoknes, 2014), highlighting personal health benefits or losses may be helpful. To promote mitigation behaviors, environmental health co-benefits may be 
emphasized. Further, highlighting the direct health consequences of climate change may promote adaptation. Overall, intervention strategies should be selected depending on people's personal values to increase their effectiveness (Steg et al., 2014). For the promotion of behaviors that have benefits for both, human health and the environment, such as meat-reduced diets and active mobility, it seems sensible to tailor the communication strategy to the audience. While for some persons, the environmental benefits might seem distal, health consequences of the respective behavior can be a more proximal motivator for change. For others, the environmental benefits might be closely related to their norms and values and even more important than the health benefits. Which benefits to emphasize should thus depend on the target group of the intervention.

\section{Conclusions}

Environmental and health issues are inherently intertwined. Much can therefore be gained by addressing environmental health systemically. Psychology has much to offer the understanding and promotion of environmental health as human behavior is a central aspect here. Environmental and health psychology both offer behavior change theory as well as systematic intervention approaches to enhance our understanding and promotion of mitigation and adaptation behaviors. As an integrated sub-discipline, environmental health psychology can capitalize on the advances and contributions of different psychology sub-disciplines to accelerate our understanding and effective mitigation of environmental issues. Thereby, psychology has the opportunity to contribute to promoting environmental health for all.

\section{References}

Abrahamse, W., Steg, L., Vlek, C., \& Rothengatter, T. (2005). A review of intervention studies aimed at household energy conservation. Journal of Environmental Psychology, 25(3), 273-291. https://doi.org/10.1016/j.jenvp.2005.08.002

Adams, C., Ide, T., Barnett, J., \& Detges, A. (2018). Sampling bias in climate - conflict research. Nature Climate Change, 8(3), 200-203. https://doi.org/10.1038/s41558-018-0068-2

Ajzen, I. (1991). The theory of planned behavior. Organizational Behavior and Human Decision Processes, 50(2), 179-211. https://doi.org/10.1016/0749-5978(91)90020-T

Akompab, D., Bi, P., Williams, S., Grant, J., Walker, I., \& Augoustinos, M. (2013). Heat waves and climate change: Applying the health belief model to identify predictors of risk perception and adaptive behaviours in Adelaide, Australia. International Journal of Environmental Research and Public Health, 10(6), 2164-2184. https://doi.org/10.3390/ijerph10062164

Andor, M. A., \& Fels, K. M. (2018). Behavioral economics and energy conservation - a systematic review of non-price interventions and their causal effects. Ecological Economics, 148, 178-210. https://doi.org/10.1016/j.ecolecon.2018.01.018

Bain, P. G., Milfont, T. L., Kashima, Y., Bilewicz, M., Doron, G., Garđarsdóttir, R. B., Gouveia, V. V., Guan, Y., Johansson, L.-O., Pasquali, C., Corral-Verdugo, V., Aragones, J. I., Utsugi, A., Demarque, C., Otto, S., Park, J., Soland, M., Steg, L., González, R., ... Saviolidis, N. M. (2016). Co-benefits of addressing climate change can motivate action around the world. Nature Climate Change, 6(2), 154-157. https://doi.org/10.1038/ nclimate2814

Bamberg, S. (2002). Effects of implementation intentions on the actual performance of new environmentally friendly behaviours - results of two field experiments. Journal of Environmental Psychology, 22(4), 399-411. https://doi.org/ 10.1006/jevp.2002.0278

Bamberg, S. (2013). Changing environmentally harmful behaviors: A stage model of self-regulated behavioral change. Journal of Environmental Psychology, 34, 151-159. https://doi.org/ 10.1016/j.jenvp.2013.01.002

Bandura, A. (1997). Self-efficacy: The exercise of control. W. H. Freeman.

Barnett, A., Akram, M., Sit, C. H.-P., Mellecker, R., Carver, A., \& Cerin, E. (2019). Predictors of healthier and more sustainable school travel mode profiles among Hong Kong adolescents. International Journal of Behavioral Nutrition and Physical Activity, 16(1), Article 48. https://doi.org/10.1186/s12966-0190807-4

Bernard, P. (2019). Health psychology at the age of Anthropocene. Health Psychology and Behavioral Medicine, 7(1), 193-201. https://doi.org/10.1080/21642850.2019.1617150

Brewer, N. T., Chapman, G. B., Gibbons, F. X., Gerrard, M., McCaul, K. D., \& Weinstein, N. D. (2007). Meta-analysis of the relationship between risk perception and health behavior: The example of vaccination. Health Psychology, 26(2), 136-145. https://doi. org/10.1037/0278-6133.26.2.136

Brügger, A., Morton, T. A., \& Dessai, S. (2015). Hand in hand: Public endorsement of climate change mitigation and adaptation. PLoS One, 10(4), e0124843. https://doi.org/10.1371/journal.pone. 0124843

Campbell-Lendrum, D., Manga, L., Bagayoko, M., \& Sommerfeld, J. (2015). Climate change and vector-borne diseases: What are the implications for public health research and policy? Philosophical Transactions of the Royal Society B: Biological Sciences, 370(1665), Article 20130552. https://doi.org/ $10.1098 /$ rstb.2013.0552

Carey, R. N., Connell, L. E., Johnston, M., Rothman, A. J., de Bruin, M., Kelly, M. P., \& Michie, S. (2019). Behavior change techniques and their mechanisms of action: A synthesis of links described in published intervention literature. Annals of Behavioral Medicine, 53(8), 693-707. https://doi.org/10.1093/abm/ kay078

Carfora, V., Catellani, P., Caso, D., \& Conner, M. (2019). How to reduce red and processed meat consumption by daily text messages targeting environment or health benefits. Journal of Environmental Psychology, 65, Article 101319. https://doi.org/ 10.1016/j.jenvp.2019.101319

Clark, M. A., Springmann, M., Hill, J., \& Tilman, D. (2019). Multiple health and environmental impacts of foods. Proceedings of the National Academy of Sciences, 116(46), 23357-23362. https:// doi.org/10.1073/pnas.1906908116

Clayton, S., Devine-Wright, P., Stern, P. C., Whitmarsh, L., Carrico, A., Steg, L., Swim, J., \& Bonnes, M. (2015). Psychological research and global climate change. Nature Climate Change, 5(7), 640-646. https://doi.org/10.1038/nclimate2622

Clayton, S., Manning, C., Krygsman, K., Speiser, M., Speiser, M., Cunsolo, A., Derr, V., Doherty, T., Fery, P., Haase, E., Kotcher, J., 
Silka, L., \& Tabola, J. (2017). Mental health and our changing climate: Impacts, implications, and guidance. American Psychological Association.

Connell, L. E., Carey, R. N., de Bruin, M., Rothman, A. J., Johnston, M., Kelly, M. P., \& Michie, S. (2019). Links between behavior change techniques and mechanisms of action: An expert consensus study. Annals of Behavioral Medicine, 53(8), 708-720. https://doi.org/10.1093/abm/kay082

Contzen, N., \& Marks, S. J. (2018). Increasing the regular use of safe water kiosk through collective psychological ownership: A mediation analysis. Journal of Environmental Psychology, 57, 45-52. https://doi.org/10.1016/j.jenvp.2018.06.008

Corner, A., Roberts, O., Chiari, S., Völler, S., Mayrhuber, E. S., Mandl, S., \& Monson, K. (2015). How do young people engage with climate change? The role of knowledge, values, message framing, and trusted communicators: Engaging young people with climate change. Wiley Interdisciplinary Reviews: Climate Change, 6(5), 523-534. https://doi.org/10.1002/wcc.353

De Dominicis, S., Schultz, P. W., \& Bonaiuto, M. (2017). Protecting the environment for self-interested reasons: Altruism is not the only pathway to sustainability. Frontiers in Psychology, 8, Article 1065. https://doi.org/10.3389/fpsyg.2017.01065

EASAC. (2019). The imperative of climate action to protect human health in Europe (EAWAC policy report 38). EASAC.

eurostat. (2020). Energy consumption in households. Eurostat Statistics Explained. https://ec.europa.eu/eurostat/web/productseurostat-news/-/DDN-20200626-1

Evans, G. W. (2019). Projected behavioral impacts of global climate change. Annual Review of Psychology, 70(1), 449-474. https://doi.org/10.1146/annurev-psych-010418-103023

Evans, L., Maio, G. R., Corner, A., Hodgetts, C. J., Ahmed, S., \& Hahn, U. (2013). Self-interest and pro-environmental behaviour. Nature Climate Change, 3(2), 122-125. https://doi.org/ 10.1038/nclimate1662

FAO. (2008). Climate change and food security: A framework document. Food and agriculture organization of the United Nations. http://www.fao.org/3/au035e/au035e.pdf

Fleetwood, S. (2019). A definition of habit for socio-economics. Review of Social Economy, 1-35. https://doi.org/10.1080/ 00346764.2019 .1630668

Frick, V., \& Santarius, T. (2019). Smarte Konsumwende? Chancen und Grenzen der Digitalisierung für den nachhaltigen Konsum [Smart consumption turnaround? Opportunities and limitations of digitalization for sustainable consumption]. In R. Huebner \& B. Schmon (Eds.), Das Transformative Potenzial von Konsum [The transformative potential of consumption between sustainability and digitalization] (pp. 37-57). Springer.

Godfray, H. C. J., Aveyard, P., Garnett, T., Hall, J. W., Key, T. J., Lorimer, J., Pierrehumbert, R. T., Scarborough, P., Springmann, M., \& Jebb, S. A. (2018). Meat consumption, health, and the environment. Science, 361(6399), eaam5324. https://doi.org/ 10.1126/science.aam5324

Goldmann, E., \& Galea, S. (2014). Mental health consequences of disasters. Annual Review of Public Health, 35(1), 169-183. https://doi.org/10.1146/annurev-publhealth-032013-182435

Gosling, S. D., \& Mason, W. (2015). Internet research in psychology. Annual Review of Psychology, 66(1), 877-902. https://doi. org/10.1146/annurev-psych-010814-015321

Hagger, M. S., \& Luszczynska, A. (2014). Implementation intention and action planning interventions in health contexts: State of the research and proposals for the way forward. Applied Psychology: Health and Well-Being, 6(1), 1-47.

Hallström, E., Carlsson-Kanyama, A., \& Börjesson, P. (2015). Environmental impact of dietary change: A systematic review. Journal of Cleaner Production, 91, 1-11. https://doi.org/ 10.1016/j.jclepro.2014.12.008
Hansstein, F. V., \& Echegaray, F. (2018). Exploring motivations behind pollution-mask use in a sample of young adults in urban China. Global Health, 14(1), Article 122. https://doi.org/ 10.1186/s12992-018-0441-y

Hardeman, W., Houghton, J., Lane, K., Jones, A., \& Naughton, F. (2019). A systematic review of just-in-time adaptive interventions (JITAls) to promote physical activity. The International Journal of Behavioral Nutrition and Physical Activity, 16(1), Article 31. https://doi.org/10.1186/s12966-019-0792-7

Houlden, V., Weich, S., de Albuquerque, J. P., Jarvis, S., \& Rees, K. (2018). The relationship between greenspace and the mental wellbeing of adults: A systematic review. PLoS One, 13(9), e0203000. https://doi.org/10.1371/journal.pone.0203000

Hunecke, M. (2013). Psychologie der Nachhaltigkeit [Psychology and sustainability]. Oekom. https://opus.bsz-bw.de/fhdo/ frontdoor/index/index/docld/1301

Inauen, J., Shrout, P. E., Bolger, N., Stadler, G., \& Scholz, U. (2016). Mind the gap? An intensive longitudinal study of betweenperson and within-person intention-behavior relations. Annals of Behavioral Medicine, 50(4), 516-522. https://doi.org/ 10.1007/s12160-016-9776-x

Inauen, J., Tobias, R., \& Mosler, H.-J. (2013). Predicting waterconsumption habits for seven arsenic-safe water options in Bangladesh. BMC Public Health, 13, 1-10. https://doi.org/ 10.1186/1471-2458-13-417

IPCC. (2014). Climate change 2014: Impacts, adaptation, and vulnerability. Part A: Global and sectoral Aspects. Contribution of working group II to the fifth assessment report of the intergovernmental panel on climate change [C. B. Field, V. R. Barros, D. J. Dokken, K. J. Mach, M. D. Mastrandrea, T. E. Bilir, M. Chatterjee, K. L. Ebi, Y. O. Estrada, R. C. Genova, B. Girma, E. S. Kissel, A. N. Levy, S. MacCracken, P. R. Mastrandrea, and L. L. White (Eds.)]. Intergovernmental Panel on Climate Change.

IPCC. (2018). Global Warming of $1.5^{\circ} \mathrm{C}$. An IPCC special report on the impacts of global warming of $1.5^{\circ} \mathrm{C}$ above pre-industrial levels and related global greenhouse gas emission pathways, in the context of strengthening the global response to the threat of climate change, sustainable development, and efforts to eradicate poverty. Intergovernmental Panel on Climate Change. https://www.ipcc.ch/sr15/

Jones, C., Hine, D. W., \& Marks, A. D. G. (2017). The future is now: Reducing psychological distance to increase public engagement with climate change. Risk Analysis, 37(2), 331-341. https://doi.org/10.1111/risa.12601

Kaiser, F. G., \& Wilson, M. (2004). Goal-directed conservation behavior: The specific composition of a general performance. Personality and Individual Differences, 36(7), 1531-1544. https://doi.org/10.1016/j.paid.2003.06.003

Kals, E. (1996). Are proenvironmental commitments motivated by health concerns or by perceived justice? In L. Montada \& M. J. Lerner (Eds.), Current societal concerns about justice (pp. 231258). Springer. https://doi.org/10.1007/978-1-4757-9927-9_13

Kelley, G. A., Kelley, K. S., \& Callahan, L. F. (2018). Communitydeliverable exercise and anxiety in adults with arthritis and other rheumatic diseases: A systematic review with metaanalysis of randomised controlled trials. BMJ Open, 8(2), e019138. https://doi.org/10.1136/bmjopen-2017-019138

Klar, M., \& Kasser, T. (2009). Some benefits of being an activist: Measuring activism and its role in psychological well-being. Political Psychology, 30(5), 755-777.

Kok, G., Schaalma, H., Ruiter, R. A. C., van Empelen, P., \& Brug, J. (2004). Intervention mapping: Protocol for applying health psychology theory to prevention programmes. Journal of Health Psychology, 9(1), 85-98. https://doi.org/10.1177/ 1359105304038379 
Künzli, N., Kaiser, R., Medina, S., Studnicka, M., Chanel, O., Filliger, P., Herry, M., Horak, F., Puybonnieux-Texier, V., Quénel, P., Schneider, J., Seethaler, R., Vergnaud, J. C., \& Sommer, H. (2000). Public-health impact of outdoor and traffic-related air pollution: A European assessment. Lancet, 356(9232), 795-801. https://doi.org/10.1016/S0140-6736(00)02653-2

Landes, F. C., Inauen, J., Ponce-Canchihuamán, J., Markowski, K., Ellis, T. K., Geen, A., \& van., (2019). Does involving parents in soil sampling identify causes of child exposure to lead? A case study of community engagement in mining-impacted towns in Peru. GeoHealth, 3(8), 218-236. https://doi.org/10.1029/ 2019GH000200

Landrigan, P. J., Fuller, R., Acosta, N. J. R., Adeyi, O., Arnold, R., Basu, N. (Nil), Baldé, A. B., Bertollini, R., Bose-O'Reilly, S., Boufford, J. I., Breysse, P. N., Chiles, T., Mahidol, C., Coll-Seck, A. M., Cropper, M. L., Fobil, J., Fuster, V., Greenstone, M., Haines, A., \& Zhong, M. (2018). The Lancet Commission on pollution and health. The Lancet, 391(10119), 462-512. https:// doi.org/10.1016/S0140-6736(17)32345-0

Lee, I.-M., Shiroma, E. J., Lobelo, F., Puska, P., Blair, S. N., \& Katzmarzyk, P. T. (2012). Effect of physical inactivity on major non-communicable diseases worldwide: An analysis of burden of disease and life expectancy. The Lancet, 380(9838), 219-229. https://doi.org/10.1016/S0140-6736(12)61031-9

Leventhal, H., Singer, R., \& Jones, S. (1965). Effects of fear and specificity of recommendation upon attitudes and behavior. Journal of Personality and Social Psychology, 2(1), 20-29. https://doi.org/10.1037/h0022089

Lewis, A., \& Edwards, P. (2016). Validate personal air-pollution sensors. Nature, 535(7610), 29-31. https://doi.org/10.1038/ $535029 a$

Lind, H. B., Nordfjærn, T., Jørgensen, S. H., \& Rundmo, T. (2015). The value-belief-norm theory, personal norms and sustainable travel mode choice in urban areas. Journal of Environmental Psychology, 44, 119-125. https://doi.org/10.1016/j.jenvp.2015. 06.001

Mach, K. J., Kraan, C. M., Adger, W. N., Buhaug, H., Burke, M., Fearon, J. D., Field, C. B., Hendrix, C. S., Maystadt, J.-F., O'Loughlin, J., Roessler, P., Scheffran, J., Schultz, K. A., \& von Uexkull, N. (2019). Climate as a risk factor for armed conflict. Nature, 571(7764), 193-197. https://doi.org/10.1038/s41586019-1300-6

Mata, J., \& Baumann, E. (2017). The dose makes the poison: Theoretical considerations and challenges of health-related POPC. In P. Vorderer, D. Hefner, L. Reinecke, \& C. Klimmt (Eds.), Permanently online, permanently connected: Living and communicating in a POPC world (pp. 254-264). Routledge, Taylor \& Francis Group. https://doi.org/10.4324/9781315276472-24

Mata, J., Thompson, R. J., Jaeggi, S. M., Buschkuehl, M., Jonides, J., \& Gotlib, I. H. (2012). Walk on the bright side: Physical activity and affect in major depressive disorder. Journal of Abnormal Psychology, 121(2), 297-308. https://doi.org/ $10.1037 / \mathrm{a} 0023533$

Matarazzo, J. D. (1980). Behavioral health and behavioral medicine: Frontiers for a new health psychology. American Psychologist, 35(9), 807-817. https://doi.org/10.1037/0003066X.35.9.807

Michie, S., Atkins, L., \& West, R. (2014). The behavior change wheel: A guide to designing interventions. Silverback Publishing.

Michie, S., Richardson, M., Johnston, M., Abraham, C., Francis, J., Hardeman, W., Eccles, M. P., Cane, J., \& Wood, C. E. (2013). The behavior change technique taxonomy (v1) of 93 hierarchically clustered techniques: Building an international consensus for the reporting of behavior change interventions. Annals of Behavioral Medicine, 46(1), 81-95. https://doi.org/10.1007/ s12160-013-9486-6
Moeller, D. W. (2011). Environmental health (4th ed.). Harvard University Press.

Mosler, H.-J. (2012). A systematic approach to behavior change interventions for the water and sanitation sector in developing countries: A conceptual model, a review, and a guideline. International Journal of Environmental Health Research, 22(5), 431-449. https://doi.org/10.1080/09603123.2011.650156

Murtagh, N., Gatersleben, B., \& Fife-Schaw, C. (2019). Occupants' motivation to protect residential building stock from climaterelated overheating: A study in southern England. Journal of Cleaner Production, 226, 186-194. https://doi.org/10.1016/ j.jclepro.2019.04.080

Nahum-Shani, I., Smith, S. N., Spring, B. J., Collins, L. M., Witkiewitz, K., Tewari, A., \& Murphy, S. A. (2018). Just-in-time adaptive interventions (JITAls) in mobile health: Key components and design principles for ongoing health behavior support. Annals of Behavioral Medicine, 52(6), 446-462. https://doi.org/10.1007/s12160-016-9830-8

Nisbet, E. K., \& Gick, M. L. (2008). Can health psychology help the planet? Applying theory and models of health behaviour to environmental actions. Canadian Psychology/Psychologie Canadienne, 49(4), 296-303. https://doi.org/10.1037/a0013277

Orbell, S., \& Sheeran, P. (1998). "Inclined abstainers": A problem for predicting health-related behaviour. British Journal of Social Psychology, 37(2), 151-165. https://doi.org/10.1111/j.20448309.1998.tb01162.x

Otto, S., Kaiser, F. G., \& Arnold, O. (2014). The critical challenge of climate change for psychology: Preventing rebound and promoting more individual irrationality. European Psychologist, 19(2), 96-106. https://doi.org/10.1027/1016-9040/a000182

Raworth, K. (2017). A doughnut for the anthropocene: Humanity's compass in the 21 st century. The Lancet Planetary Health, 1(2), e48-e49. https://doi.org/10.1016/S2542-5196(17)30028-1

Rogers, R. W. (1975). A protection motivation theory of fear appeals and attitude change. Journal of Psychology, 91(1), 93-114. https://doi.org/10.1080/00223980.1975.9915803

Sauerborn, R., \& Ebi, K. (2012). Climate change and natural disasters - integrating science and practice to protect health. Global Health Action, 5(1), Article 19295. https://doi.org/ 10.3402/gha.v5i0.19295

Schultz, P. W., Messina, A., Tronu, G., Limas, E. F., Gupta, R., \& Estrada, M. (2016). Personalized normative feedback and the moderating role of personal norms: A field experiment to reduce residential water consumption. Environment and Behavior, 48(5), 686-710. https://doi.org/10.1177/ 0013916514553835

Schwarzenbach, R. P., Egli, T., Hofstetter, T. B., von Gunten, U., \& Wehrli, B. (2010). Global water pollution and human health. Annual Review of Environment and Resources, 35(1), 109-136. https://doi.org/10.1146/annurev-environ-100809-125342

Schwarzer, R. (2008). Modeling health behavior change: How to predict and modify the adoption and maintenance of health behaviors. Applied Psychology, 57(1), 1-29. https://doi.org/ 10.1111/j.1464-0597.2007.00325.x

Schwarzer, R., Lippke, S., \& Luszczynska, A. (2011). Mechanisms of health behavior change in persons with chronic illness or disability: The Health Action Process Approach (HAPA). Rehabilitation Psychology, 56(3), 161-170. https://doi.org/10.1037/ a0024509

Sniehotta, F. F., Scholz, U., \& Schwarzer, R. (2005). Bridging the intention-behaviour gap: Planning, self-efficacy, and action control in the adoption and maintenance of physical exercise. Psychology \& Health, 20(2), 143-160. https://doi.org/10.1080/ 08870440512331317670

Steffen, W., Richardson, K., Rockström, J., Cornell, S. E., Fetzer, I., Bennett, E. M., Biggs, R., Carpenter, S. R., de Vries, W., de Wit, 
C. A., Folke, C., Gerten, D., Heinke, J., Mace, G. M., Persson, L. M., Ramanathan, V., Reyers, B., \& Sörlin, S. (2015). Planetary boundaries: Guiding human development on a changing planet. Science, 347(6223), 1-11. https://doi.org/10.1126/science. 1259855

Steg, L., Bolderdijk, J. W., Keizer, K., \& Perlaviciute, G. (2014). An integrated framework for encouraging pro-environmental behaviour: The role of values, situational factors and goals. Journal of Environmental Psychology, 38, 104-115. https://doi. org/10.1016/j.jenvp.2014.01.002

Steg, L., \& Vlek, C. (2009). Encouraging pro-environmental behaviour: An integrative review and research agenda. Journal of Environmental Psychology, 29(3), 309-317. https://doi.org/ 10.1016/j.jenvp.2008.10.004

Steinhorst, J., Klöckner, C. A., \& Matthies, E. (2015). Saving electricity - for the money or the environment? Risks of limiting pro-environmental spillover when using monetary framing. Journal of Environmental Psychology, 43, 125-135. https:// doi.org/10.1016/j.jenvp.2015.05.012

Stern, P. C. (2011). Contributions of psychology to limiting climate change. American Psychologist, 66(4), 303-314. https://doi.org/ 10.1037/a0023235

Stern, P. C., Dietz, T., Abel, T., Guagnano, G. A., \& Kalof, L. (1999). A value-belief-norm theory of support for social movements: The case of environmentalism. Human Ecology Review, 6(2), 81-97.

Stoknes, P. E. (2014). Rethinking climate communications and the "psychological climate paradox". Energy Research \& Social Science, 1, 161-170. https://doi.org/10.1016/j.erss.2014.03.007

Swinburn, B. A., Kraak, V. I., Allender, S., Atkins, V. J., Baker, P. I., Bogard, J.R., Brinsden, H., Calvillo, A., De Schutter, O., Devarajan, R., Ezzati, M., Friel, S., Goenka, S., Hammond, R. A., Hastings, G., Hawkes, C., Herrero, M., Hovmand, P. S., Howden, M., \& Dietz, W. H. (2019). The global syndemic of obesity, undernutrition, and climate change: The Lancet Commission report. The Lancet, 393(10173), 791-846. https://doi. org/10.1016/S0140-6736(18)32822-8

Thunberg, G. (2019). No one is too small to make a difference. Penguin.

van den Broek, K., Bolderdijk, J. W., \& Steg, L. (2017). Individual differences in values determine the relative persuasiveness of biospheric, economic and combined appeals. Journal of Environmental Psychology, 53, 145-156. https://doi.org/10.1016/ j.jenvp.2017.07.009

van Valkengoed, A., \& Steg, L. (2019). The psychology of climate change adaptation (1st ed.). Cambridge University Press. https://doi.org/10.1017/9781108595438

Varotto, A., \& Spagnolli, A. (2017). Psychological strategies to promote household recycling. A systematic review with metaanalysis of validated field interventions. Journal of Environmental Psychology, 51, 168-188. https://doi.org/10.1016/ j.jenvp.2017.03.011

Verplanken, B., Roy, D., \& Whitmarsh, L. (2018). Cracks in the wall: Habit discontinuities as vehicles for behaviour change. In B. Verplanken (Ed.), The psychology of habit: Theory, mechanisms, change, and contexts (pp. 189-205). Springer International Publishing. https://doi.org/10.1007/978-3-319-97529-0_11

Watts, N., Adger, W. N., Agnolucci, P., Blackstock, J., Byass, P., Cai, W., Chaytor, S., Colbourn, T., Collins, M., Cooper, A., Cox, P. M., Depledge, J., Drummond, P., Ekins, P., Galaz, V., Grace, D., Graham, H., Grubb, M., Haines, A., ... Costello, A. (2015). Health and climate change: Policy responses to protect public health. The Lancet, 386(10006), 1861-1914. https://doi.org/ 10.1016/S0140-6736(15)60854-6
Weinstein, N. D., Lyon, J. E., Sandman, P. M., \& Cuite, C. L. (1998) Experimental evidence for stages of health behavior change: The precaution adoption process model applied to home radon testing. Health Psychology, 17(5), 445-453. https://doi.org/ 10.1037/0278-6133.17.5.445

WHO. (2019). Ambient air pollution: Health impacts. https://www. who.int/airpollution/ambient/health-impacts/en/

Zander, K. K., Richerzhagen, C., \& Garnett, S. T. (2019). Human mobility intentions in response to heat in urban South East Asia. Global Environmental Change, 56, 18-28. https://doi.org/ 10.1016/j.gloenvcha.2019.03.004

Zhang, Q. C., Schwarzer, R., \& Hagger, M. (2019). A meta-analysis of the health action process approach. Health Psychology, 38(7), 623-637. https://doi.org/10.1037/hea0000728

Zhou, G., Gan, Y., Ke, Q., Knoll, N., Lonsdale, C., \& Schwarzer, R. (2016). Avoiding exposure to air pollution by using filtering facemask respirators: An application of the health action process approach. Health Psychology, 35(2), 141-147. https:// doi.org/10.1037/hea0000264

\section{History}

Received February 29, 2020

Revision received December 11, 2020

Accepted January 26, 2021

Published online July 15, 2021

\section{Funding}

Josianne Kollmann received funding from the German Research Foundation (DFG; FOR 2374).

\section{ORCID}

Jennifer Inauen

(iD https://orcid.org/0000-0002-7884-3222

\section{Jennifer Inauen}

Department of Health Psychology and Behavioral Medicine Institute of Psychology

University of Bern

Fabrikstrasse 8

3012 Bern

Switzerland

jennifer.inauen@psy.unibe.ch

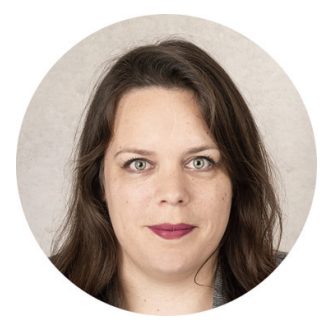

Jennifer Inauen (PhD) is Assistant Professor (tenure track) of Health Psychology in the Department of Health Psychology and Behavioral Medicine at University of Bern, Switzerland. Her research aims to understand the principles of behavior change, which she studies at the example of healthy eating, hygiene, safe water consumption, and more. She is a member of the Board of Promotion and Prevention of the European Federation of Psychologists' Associations. 


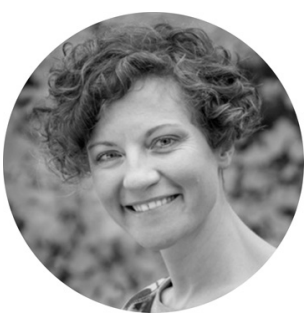

Nadja Contzen (PhD) is group leader (tenure track) of the Environmental Health Psychology Group in the department of Environmental Social Sciences at Eawag (the water research institute of ETH), Switzerland, and research affiliate in the Environmental Psychology Group at the University of Groningen, the Netherlands. With her research, she aims at increasing our knowledge on the underlying mechanisms of environmental health behaviors and the social acceptance of sustainable policies and innovations. She uses this knowledge to develop effective interventions to promote environmental health behaviors and acceptance of sustainable policies and innovations.

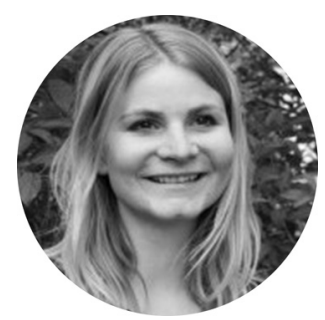

Vivian Frick is a researcher and PhD candidate at the Institute of Ecological Economy Research (IÖW) in Berlin. Her research is in the field of environmental psychology and socialecological transformation, with a transdisciplinary approach and a focus on sustainable consumption, sufficiency and digital transformation. Besides, she is active in the Initiative Psychologie im Umweltschutz (IPU) and Wandelwerk e.V.

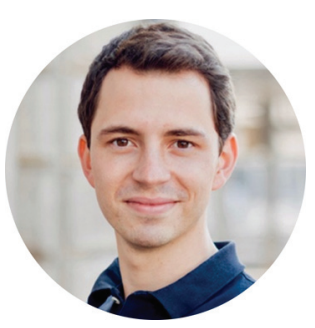

Philipp Kadel is a researcher and PhD student at the Department of Health Psychology and the Center for Doctoral Studies in Social and Behavioral Sciences at the University of Mannheim, Germany. In his research, he focuses on behaviors simultaneously beneficial for both the environment and human health, like following a meat-reduced diet. $\mathrm{He}$ is active in a Committee and a Special Interest Group within the European Health Psychology Society (EHPS) and the Psychology Coalition at the United Nations (PCUN).

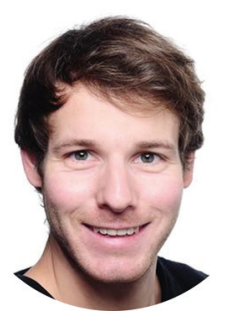

Jan Keller (PhD) is working as a postdoctoral research fellow at the Division of Health Psychology, Freie Universität Berlin, Germany. His research aims to gain more insights about the role of social exchange processes and habit formation for health promotion. He is an Executive Committee member of a sub-division of the European Health Psychology Society (EHPS).

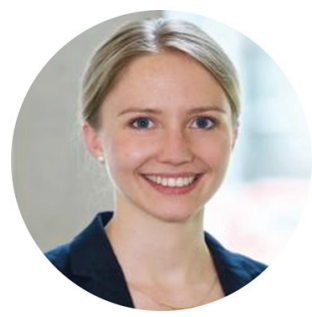

Josianne Kollmann is a research scientist and PhD student at the Department of Psychological Assessment and Health Psychology at the University of Konstanz, Germany. Her research aims at understanding the psychological aspects of health risk perceptions and health behavior. She has investigated trajectories in risk perceptions across time after personalized health risk feedback as well as the interplay between health behavior and risk perceptions.

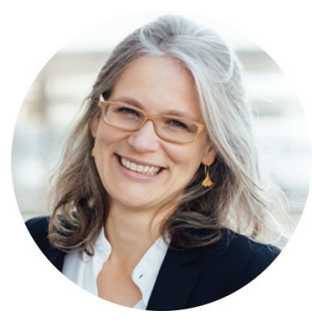

Jutta Mata is Professor of Health Psychology at the University of Mannheim, Germany, and associated research scientist at the Max Planck Institute for Human Development, Berlin, the Mannheim Centre for European Social Research, and the University of Lisbon, Portugal. Her main research topics include understanding individual and environmental factors that determine health behaviors - particularly nutrition and physical activity - and the effects of health behaviors on well-being. Jutta Mata is Treasurer and member of the Executive Committee of the European Health Psychology Society (EHPS).

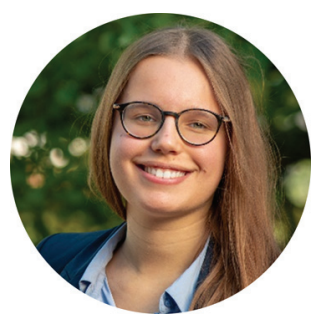

Anne van Valkengoed is a PhD candidate at the University of Groningen. Her research is focused on understanding the psychological motivations underlying individuals' and households' decisions to adapt to climate change. 